\title{
O que informam os Formulários de Referência sobre as Características e Remuneração de Executivos?
}

\section{What does the Reference Form reports about Characteristics and Executive Compensation?}

\author{
Jean Carlo Rissatti \\ Mestrando em Contabilidade - PPGC/UFSC \\ Universidade Federal de Santa Catarina
}

Campus Universitário Reitor David Ferreira Lima, Trindade - Florianópolis, SC, 88040-380

E-mail: rissatti.jean@gmail.com

Telefone: (48) 3721-9897

\author{
João Antônio Salvador de Souza \\ Doutorando em Contabilidade - PPGC/UFSC \\ Universidade Federal de Santa Catarina
}

Campus Universitário Reitor David Ferreira Lima, Trindade - Florianópolis, SC, 88040-380

E-mail: jass26salvador@gmail.com

Telefone: (48) 3721-9897

\author{
José Alonso Borba \\ Doutor em Controladoria e Contabilidade pela Universidade de São Paulo. \\ Professor do Departamento de Ciências Contábeis da Universidade Federal de Santa Catarina \\ - CCN/PPGC/UFSC \\ Campus Universitário Reitor David Ferreira Lima, Trindade - Florianópolis, SC, 88040-380 \\ E-mail: j.alonso@ufsc.br \\ Telefone: (48) 3721-9897
}

\section{Resumo}

Utilizados como mecanismos para minimizar o conflito de interesses, os instrumentos de remuneração executiva estão associados às metas das empresas bem como as características dos gestores. Este artigo tem como objetivos: (i) mapear os tipos de remuneração dos executivos; e (ii) identificar os determinantes da remuneração dos conselheiros administrativos, diretores estatutários e conselheiros ficais. Para operacionalizar a pesquisa, foi composta uma amostra entre 2013 a 2016 com as companhias abertas que integravam o índice Ibovespa de 2017. As variáveis de remuneração executiva e característica dos conselheiros foram coletadas manualmente dos formulários de referência, sendo analisadas as características de 3.923 executivos/anos. Pela análise econométrica foi possível identificar que: (i) conselhos maiores influenciam diretamente os planos remuneratórios; (ii) a presença de mulheres torna a remuneração mais conservadora; (iii) a dualidade de cargos reduz a remuneração executiva; (iv) a falta de independência tem impacto negativo na compensação dos executivos; (v) empresas com maior rentabilidade tendem a remunerar melhor seus executivos e; (vi) os planos de remuneração dos executivos de empresas controladas pelo Estados são menores do que as não controladas pelo governo. Os achados são úteis para os participantes do mercado, que podem relacionar seus investimentos prospectivos com o perfil e tipos de remunerações dos executivos.

Palavras - chave: Conflito de Interesses; Remuneração Executiva; Pagamento Baseado em Ações. 


\begin{abstract}
Used as mechanism to minimize the conflicts of interests, the executive compensation instruments are associated with corporate objectives as well as the managers' characteristics. This article aims to: (i) map the types of executive compensation; and (ii) identify the determinants of the compensation of directors, statutory directors and the fiscal council. In order to operationalize this research, the sample was composed between 2013 and 2016 with public companies that were included in 2017 Ibovespa Index. The variables of executives' compensation and characteristics were manually collected from the reference form, were analyzed the characteristics of 3.923 executives/year. Through econometric analysis was possible to identify that: (i) large boards directly influence the compensation plans; (ii) the female participation turns the compensation more conservative; (iii) the duality of positions reduces the compensation; (iv) the lack of independence has a negative impact in the remuneration; (v) companies with greater profitability tend to pay better the executives; and (vi) compensation plans for executives of State-controlled companies are smaller than those not controlled by the government. The findings are useful to market participants, who can relate their prospective investments with the executive's profiles and the types of executive compensation.
\end{abstract}

Keywords: Conflict of Interest; Executive Compensation; Stock-Based Compensation.

\title{
1 Introdução
}

A remuneração dos executivos é utilizada no alinhamento entre os interesses da empresa com os da alta gestão. As companhias passaram a remunerar seus executivos além das formas tradicionais do mercado, através, por exemplo, do pagamento de cursos de especialização, de treinamentos no exterior e de planos de benefícios diversos (CORTEZ, 2012). Os instrumentos de remuneração visam alcançar os objetivos organizacionais na perspectiva de atingir benefícios futuros com a longevidade da manutenção dos colaboradores (WOOD JUNIOR; PICARELLI FILHO, 1999).

Com as recentes oscilações econômicas, as empresas passaram a rever os planos de remuneração dos empregados, dado que as metas estipuladas não estavam sendo realizadas (SIGOLLO, 2015). Ainda segundo o autor, a remuneração variável, em termos percentuais, foi afetada, acarretando aumento do salário-base e diminuição dos incentivos de curto prazo (bônus).

Dentre os tipos de remuneração variável, destaca-se o pagamento baseado em ações. Este apresenta características distintas, como a diluição do capital e a garanti dos direitos de acionistas, considerando-se que as ações conferem direito a recebimento de dividendos e podem conceder direito a voto nas assembleias gerais, tal como disciplinado na Lei 6.404 de 1976. Frydman e Jenter (2010) observaram que durante os anos 80 e 90 as stocks options, um dos tipos de pagamento baseado em ações, representavam as maiores parcelas da remuneração dos executivos. Um aspecto relevante levantado por Lipman e Hall (2008) é que a porcentagem de remuneração baseada em ações dentro do pacote de compensação não deve ser consideravelmente elevada devido ao potencial conflito de interesses entre principal-agente, haja vista que gestores oportunistas podem concentrar esforços para a valorização discricionária do preço das ações. Para Lawler III (1990), a parcela variável da remuneração pode ser considerada vantagem competitiva. Por esta ótica, os sistemas de remuneração, alinhados às estratégias empresariais, podem melhorar a eficácia organizacional (LAWLER III, 1990), acarretando melhora no desempenho global das empresas (ATTAWAY, 2000; EL-SAYED; ELBARDAN, 2016; OZKAN, 2011) 
$\mathrm{Na}$ tentativa de minimizar o conflito de agência e alinhar os interesses entre as partes relacionadas, as companhias passaram a estruturar pacotes de remuneração aos executivos. $\mathrm{O}$ instrumento de remuneração baseado em ações, assim como os planos de stock options, que consistem em oferecer aos empregados a opção de compra de ações a valores abaixo do mercado, podem minimizar os problemas de agência (FIRTH; TAM; TANG, 1999).

Silveira e Barros (2013) desenvolveram um indicador que captura as características da homogeneidade do Conselho de Administração, doravante CA, considerando características de porcentagem de mulheres, mandatos médios, características educacionais e de permanência no conselho. Souza (2014), de forma adicional em sua pesquisa, utilizou essas características para identificar os determinantes do excesso de remuneração dos executivos. O autor verificou relação estatisticamente significativa entre as características sugeridas por Silveira e Barros (2013) e a remuneração total das empresas.

A literatura que explica as determinantes da remuneração dos executivos é extensa (por exemplo ver: Bereskin e Cicero (2013), Core, Guay e Larcker (2008) e Mehran (1995) para os EUA; Conyon (1997) e Shiwakoti (2012) para o Reino Unido; Kato, Kim e Lee(2007) para a Coreia; Firth, Fung e Rui (2006) para a China; O’Neill e Iob (1999) para a Austrália; Hearn (2013) para o mercado do norte do continente africano), porém, a relação empírica da remuneração como mecanismo de governança corporativa ainda precisa ser validada devido os resultados dos estudos serem conflitantes. Davis (1979) não identificou relação entre idade do executivo e desempenho organizacional. Bertrand e Schoar (2003) sugerem que executivos mais velhos são mais conservadores. Funchal e Terra (2006), em estudo multipaíses incluindo o Brasil, identificaram um número reduzido de conselheiros independentes e uma menor participação dos executivos no CA.

Na presente pesquisa pretende-se responder a seguinte questão: quais são os tipos e os determinantes da remuneração executiva no mercado acionário brasileiro? Deste modo, o objetivo do trabalho é mapear os tipos, bem como identificar os determinantes da remuneração dos executivos que compõem o Conselho de Administração, a Diretoria Estatutária e o conselho fiscal das empresas com ações negociadas no mercado acionário brasileiro.

Para testar a relação entre a remuneração e a característica dos executivos, foram selecionadas as 59 empresas que integravam o índice Ibovespa de 2017. As informações foram coletadas manualmente no formulário de referencia (FR), perfazendo os anos de 2013 a 2016. Inicialmente, a remuneração executiva foi segregada em fixa, variável e por meio de pagamento baseado em ações. As características dos conselheiros administrativos, diretores e conselheiros fiscais analisadas foram a quantidade de membros dos conselhos, o grau de instrução, a dualidade e a independência. Para controlar o efeito do desempenho na remuneração, foram selecionadas variáveis que representam a magnitude da rentabilidade, estas coletadas das demonstrações financeiras das empresas.

A pesquisa apresenta relevância por analisar tipos específicos de remuneração variável. No mercado acionário brasileiro, empresas como Ambev adicionaram ao longo dos anos componentes variáveis para compor substancial parcela da remuneração total executiva (ABRANTES, 2016). Já empresas como a Petrobras, adotaram planos de carreira para seus colaboradores mediante remuneração por desempenho (RAMALHO, 2018). Não obstante, existem métodos de remuneração em que o capital dos acionistas é diluído e outros não, o que pode agravar o conflito de interesses. Neste ponto, para minimizar o problema de agência, autores como Balsam (2002), Ellig (2007) e Murphy (2013) propõem que determinados elementos dos planos de remuneração variável não sejam atrelados ao desempenho corrente, mas sim, realizados em um conjunto de anos. Corroboram com essas conjecturas, as pesquisas de Hanlon, Rajgopal e Shevlin (2003) e Lin, Kuo e Wang (2013), que demonstram empiricamente uma relação positiva entre pagamentos de incentivos e lucros operacionais futuros. . Neste contexto, o presente estudo estende a literatura ao verificar quais os tipos de 
remuneração variável são praticados no mercado acionário brasileiro, bem como sua relação com as características dos executivos.

Os resultados podem ser úteis para os participantes do mercado. Outrossim, como as empresas remuneram, podem ser úteis na relação entre as perspectivas de investimentos futuras. Os achados também podem auxiliar os reguladores a monitorar as práticas de remuneração das empresas objetivando atenuar e manifestar possíveis problemas de agência.

\section{Referencial Teórico}

\subsection{Conflito de Interesses}

O modelo mais abordado nos estudos relacionados à remuneração executiva considera a perspectiva do problema de agência proposto por Jensen e Meckling (1976) (BEBCHUK; FRIED; WALKER, 2002; CONYON, 2006). O problema de agência surge da relação de quando uma ou mais pessoas (o principal) possuem uma relação contratual com outra pessoa (o agente) que tomará decisões a respeito da empresa em seu nome. Pela perspectiva do problema de agência, o conflito de interesses existe quando o agente objetiva maximizar seu bem-estar pessoal em detrimento dos objetivos econômicos do principal. Assim, este deverá alinhar seus interesses ao dos gestores.

Neste contexto, os contratos de remuneração são importantes instrumentos da governança corporativa, auxiliando no alinhamento de interesses entre as partes (CORE; GUAY; LARCKER, 2003). Deste modo, os planos de remuneração estão relacionados com as melhores práticas de governança corporativa, possibilitando a maximização de recursos e a motivação dos executivos (BALSAM, 2002) e possibilitando na continuidade desses nas empresas (CONYON, 2006).

As empresas buscam implantar melhores incentivos para alinhamento de interesses, tal como, por exemplo, a retenção de pessoal qualificado. Segundo Bebchuk e Fried (2004), distúrbios causados pela remuneração de executivos decorrem de problemas básicos de governança, uma vez que os incentivos para aumentar o valor para os acionistas não são considerados suficientes. Já para Lipman e Hall (2008), devem ser incluídos nos planos de remuneração componentes patrimoniais aos de caixa para melhor alinhamento de interesses.

Autores como Jensen e Murphy (1990) mostram que algumas empresas aumentam a participação dos funcionários nas companhias sob a concepção de que quanto maior for a parcela dos executivos e da alta administração nas ações da empresa, maior será a ligação entre as riquezas dos acionistas e dos executivos.

As remunerações baseadas em ações e opções de ações deixam os executivos expostos às influências do mercado, ao contrário da compensação fixa (ELLIG, 2007). Devido esta exposição ao risco, os executivos podem gerenciar o desempenho das empresas para atingir suas metas remuneratórias (BENNETT et al., 2017). Para Jensen e Murphy (1990), uma elevada parcela de capital próprio das empresas atrelada aos executivos evitaria a manipulação gerencial danosa às empresas.

A remuneração pode ser instrumento utilizado para alinhamento de interesses do gestor com os da empresa, todavia, como Jensen e Murphy (1990, p. 2) informam "existem sérios problemas com a compensação dos executivos, mas o pagamento 'excessivo' não é o maior problema - e sim como são pagos", além disso, "a política de compensação não apenas molda como os executivos se comportam, mas também ajuda a determinar que tipo de executivos uma organização atrai" (JENSEN: MURPHY, 1990, p. 4).

A remuneração em primazia é composta por uma parcela fixa e outra variável. Esta é obtida através de metas pré-estabelecidas pela administração, podendo ser atrelada a indicadores econômico-financeiros, ambientais e sociais. Já aquela visa à redução do risco do executivo, contudo, minimiza o interesse em obter valor para o acionista. 
Existem diversos elementos que compõem os pacotes de remuneração. Balsam (2002) classifica os tipos mais comuns de remuneração como sendo: salário, bônus, opção de ações (stock options), concessão de ações (stock grants), pensões, benefícios e gratificações. Já Murphy (1999) divide os componentes da remuneração em: salários-base, planos de bônus anual, stock options, restricted stock, planos de incentivos de longo prazo e planos de aposentadoria. Enquanto que para Frydman e Jenter (2010) os pacotes são compostos por cinco elementos básicos: salário, bônus anual, pagamentos de planos de incentivo de longo prazo, concessões de opções restritas e ações restritas.

Recomendações existem para elaboração dos pacotes de remuneração, entretantoa escolha para incentivos específicos também dependem da filosofia e cultura da empresa e de seu plano estratégico (LIPMAN; HALL, 2008); além disso, não há pacotes que alinhem perfeitamente os interesses entre ambas as partes (BEBCHUK; FRIED; WALKER, 2002), porém, os comitês de remuneração incluem opções de ações, ações restritas e contratos de longo prazo para tentar criar pacotes que forneçam incentivos adequados aos CEOs - Chief Executive Officer (CONYON, 2006).

\subsection{Pagamento baseado em ações}

O pagamento baseado em ações passou a ter relevância como atenuante do conflito de interesses. Por exemplo, as stock options surgiram na década de 80, com o objetivo de atrelar a compensação ao preço das ações, fornecendo incentivos aos executivos para maximização do valor para os acionistas (FRYDMAN; JENTER, 2010).

No estudo de Frydman e Jenter (2010), observou-se que durante os anos 80 e 90 as stocks options representavam as maiores parcelas da remuneração dos executivos, porém, após a chamada bolha tecnológica de 2000 e 2001, as concessões de ações restritas (restricted stocks) passaram ser a forma mais popular de compensação.

Aspecto importante levantado por Lipman e Hall (2008), a porcentagem de remuneração baseada em ações não deve ser substancialmente elevada, a fim de evitar que o foco dos executivos seja unicamente o aumento do preço das ações da empresa em detrimento do desempenho operacional. Os autores alertam, todavia, que o pagamento baseado em ações deve ser representativo dentro do plano de remuneração. Devido ao contexto do estudo de Lipman e Hall (2008), mercado norte-americano, a parcela de pagamentos baseados em ações no plano de remuneração parece estar alinhada à estratégia de manutenção dos executivos nos cargos de alta direção.

Na Tabela 1 são apresentadas algumas características, vantagens e/ou desvantagens dentre os tipos de pagamentos baseado em ações, de acordo com a literatura.

Tabela 1 - Características e/ou vantagens e desvantagens dos tipos de pagamentos baseado em ações.

\begin{tabular}{|l|c|c|c|c|}
\hline \multicolumn{1}{|c|}{ Características e/ou vantagens e desvantagens } & $\begin{array}{c}\text { Stock } \\
\text { options }\end{array}$ & SARs & $\begin{array}{c}\text { Restricte } \\
\text { d Stocks }\end{array}$ & $\begin{array}{c}\text { Phanton } \\
\text { Stocks }\end{array}$ \\
\hline Torna-se um acionista imediatamente. & Não & Não & Sim & Não \\
\hline Direito e privilégios de acionistas (por exemplo: dividendos). & & Não & Sim & Não* \\
\hline $\begin{array}{l}\text { Recompensam os executivos que não contribuíram para o } \\
\text { crescimento passado da empresa. }\end{array}$ & Não & Sim & \\
\hline Reduz ganhos básicos por ação. & Sim & Sim & Sim & \\
\hline Aumenta o número de ações emitidas e em circulação. & Sim & Não & Sim & Não \\
\hline Recompensa o executivo por aumentos no valor. & Sim & Sim & Não & \\
\hline Utiliza menos ações para entregar valor equivalente. & Não & Não & & Sim \\
\hline Exigir o pagamento de qualquer preço no momento de exercício. & Sim & Não & Não & Não \\
\hline
\end{tabular}




\begin{tabular}{|l|c|c|c|c|} 
Executivos compartilham da perda. & Não & Não & Sim & \\
\hline Pode ser baseado no tempo ou desempenho. & Sim & Sim & Sim & Sim \\
\hline Necessário manter as ações por um período depois do exercício. & Sim & & & \\
\hline $\begin{array}{l}\text { Direito de comprar ações a valor justo de mercado ou um desconto, } \\
\text { ou os funcionários podem receber ações sem custo. }\end{array}$ & & & Sim & \\
\hline $\begin{array}{l}\text { Direito de comprar um número de açães a um preço fixado na } \\
\text { concessão por um número definido de anos no futuro. }\end{array}$ & Sim & & & \\
\hline $\begin{array}{l}\text { É vantajoso para o executivo se o valor da ação (data de exercício) } \\
\text { estiver acima do valor da ação (data de concessão) }\end{array}$ & Sim & & & \\
\hline $\begin{array}{l}\text { É necessário comprar as ações e depois vende-las para se obter } \\
\text { lucro. }\end{array}$ & Sim & & & \\
\hline $\begin{array}{l}\text { Paga bônus em dinheiro futuro igual ao valor de certo número de } \\
\text { ações. }\end{array}$ & & & & Sim \\
\hline Direito de receber prêmio com base no valor da ação da empresa. & & Sim & & Sim \\
\hline $\begin{array}{l}\text { Executivo pode se desligar da empresa caso o preço das ações não } \\
\text { exceder o preço da opção. }\end{array}$ & Sim & Sim & & \\
\hline Maior risco para o executivo. & Sim & & Não & \\
\hline
\end{tabular}

Fonte: Elaborado pelos autores com base em Balsam (2002), Ellig (2007), Giroux (2015) e Lipman e Hall (2008).

Nota: *direitos equivalentes a dividendos. SARs: Stock Appreciation Rights. Phanton Stocks: Ações fantasmas.

De acordo com Lipman e Hall (2008), uma das medidas para se evitar algumas das desvantagens trazidas pelas ações restritas é aderir a metas de desempenho para que as restrições expirem. As empresas poderiam então, por exemplo, estupular tempo de contrato de 5 a 10 anos.

Existe diversidade de estudos relacionando as características dos conselhos ao desempenho das companhias e remuneração executiva. No Quadro 1 é apresentada uma síntese dos estudos anteriores.

\section{Quadro 1 - Estudos relacionados}

\begin{tabular}{|c|c|c|}
\hline Autor & $\begin{array}{l}\text { Amostra e/ou Procedimento } \\
\text { metodológico }\end{array}$ & Resultados gerais \\
\hline $\begin{array}{l}\text { Bajtelsmit e } \\
\text { Bernasek } \\
(1996)\end{array}$ & Pesquisa de revisão de literatura. & $\begin{array}{l}\text { Sugeriram que a presença de mulheres torna as decisões } \\
\text { mais conservadoras quando da análise de investir suas } \\
\text { pensões. }\end{array}$ \\
\hline $\begin{array}{l}\text { Jianakoplos e } \\
\text { Bernasek } \\
\text { (1998) }\end{array}$ & $\begin{array}{l}\text { Analisaram } 3.143 \text { respondentes } \\
\text { constantes na base de dados Federal } \\
\text { Reserve System. }\end{array}$ & $\begin{array}{l}\text { As mulheres são relativamente mais avessas ao risco do } \\
\text { que os homens ao tomar decisões financeiras. }\end{array}$ \\
\hline $\begin{array}{l}\text { Kiel e } \\
\text { Nicholson } \\
(2003)\end{array}$ & $\begin{array}{l}\text { Utilizaram como base de dados as } \\
348 \text { maiores empresas listadas da } \\
\text { Austrália, para o ano de } 1996 .\end{array}$ & $\begin{array}{l}\text { Encontraram correlação positiva entre o tamanho do } \\
\text { conselho e o valor da empresa. }\end{array}$ \\
\hline $\begin{array}{l}\text { Kuhn e Yockey } \\
\qquad(2003)\end{array}$ & Pesquisa experimental. & $\begin{array}{l}\text { Identificaram que as preferências de risco dependem da } \\
\text { natureza do plano de remuneração, e a preferência pela } \\
\text { opção mais arriscada se dá em relação ao desempenho } \\
\text { individual e não quando associada a desempenho } \\
\text { coletivo. }\end{array}$ \\
\hline $\begin{array}{c}\text { Ghosh e } \\
\text { Sirmans (2005) }\end{array}$ & $\begin{array}{l}\text { Investigaram } 330 \text { fundos de } \\
\text { investimentos mobiliários nos anos } \\
\text { de } 1998,1999 \text { e } 2000 .\end{array}$ & $\begin{array}{l}\text { Além dos determinantes econômicos as empresas devem } \\
\text { incluir variáveis de estrutura de administração e de } \\
\text { propriedade nos pacotes de compensação. }\end{array}$ \\
\hline
\end{tabular}




\begin{tabular}{|c|l|l|}
\hline $\begin{array}{c}\text { Campbell e } \\
\text { Mínguez-Vera } \\
(2008)\end{array}$ & $\begin{array}{l}\text { Investigaram 68 empresas não } \\
\text { financeiras listadas na Espanha, } \\
\text { durante o período de janeiro de } \\
1995 \text { a dezembro de 2000. }\end{array}$ & $\begin{array}{l}\text { O valor da empresa não é afetado apenas pela presença de } \\
\text { mulheres no CA, no entanto, a diversidade teve um } \\
\text { impacto positivo no valor da empresa. }\end{array}$ \\
\hline $\begin{array}{c}\text { Fernandes } \\
(2008)\end{array}$ & $\begin{array}{l}\text { Estudaram 51 empresas listadas no } \\
\text { mercado acionário de Portugal } \\
\text { entre os anos de 2002 a 2004. }\end{array}$ & $\begin{array}{l}\text { Os conselhos que possuem mais membros não executivos } \\
\text { pagam salários mais altos e que empresas sem a } \\
\text { participação de membros não executivos nos conselhos } \\
\text { têm um melhor alinhamento entre os interesses dos } \\
\text { administradores e dos acionistas. }\end{array}$ \\
\hline $\begin{array}{c}\text { Elkinawy e } \\
\text { Stater (2011) }\end{array}$ & $\begin{array}{l}\text { Investigaram 18.742 executivos } \\
\text { para o período de 1992 a 2004. }\end{array}$ & $\begin{array}{l}\text { Demonstraram efeitos positivos sobre o desempenho, } \\
\text { porém dependendo fortemente das qualificações das } \\
\text { mesmas. }\end{array}$ \\
\hline Peni (2014) & $\begin{array}{l}\text { Estudou 305 empresas do mercado } \\
\text { acionário norte americano, } \\
\text { compreendendo um período entre } \\
\text { 2006 e 2010 }\end{array}$ & $\begin{array}{l}\text { Relação positiva entre a presença de mulheres nos cargos } \\
\text { de executivo e presidente do conselho, tal como no } \\
\text { desempenho da empresa. }\end{array}$ \\
\hline
\end{tabular}

Fonte: Elaborado pelos autores.

\section{Procedimentos metodológicos}

\subsection{Seleção de dados e tratamento da amostra}

Inicialmente a amostra foi composta pelas 59 empresas que compunham o índice Ibovespa (IBOV) referente ao período de janeiro a abril de 2017. Este índice tem como objetivo medir o desempenho médio das cotações dos ativos de maior negociabilidade e representatividade do mercado de ações brasileiro.

Após a definição da amostra, foram coletados os dados para remuneração dos executivos nos formulários de referência (FR) emitidos em 2013, 2014, 2015 e 2016. O item 13 do FR foi utilizado para composição dos valores remuneratórios. Para identificação das características dos executivos utilizou-se o item 12 do FR. Após essa coleta, foram selecionadas as informações financeiras, estas, obtidas do banco de dados Economatica®.

No procedimento de construção da amostra, inicialmente foram excluídas as empresas do setor financeiro e áreas afins devido às diferenças estruturais, operacionais e financeiras (HEALY; WAHLEN, 1999). Posteriormente foram excluídas as empresas com ações em duplicidade no IBOV. Por fim, foram excluídas as empresas com dados faltantes para o cálculo das variáveis. Após os ajustes, a amostra findou em 43 empresas, sendo 170 empresas/anos.

\subsection{Definição teórica e operacional das variáveis}

\section{Variáveis dependentes: remuneração executiva}

A remuneração executiva pode ser ramificada em sua parte fixa e variável. A literatura também apoia que a remuneração executiva seja medida pelo desempenho baseado em ações (MURPHY, 1999). Com isso, a variável remuneração total foi estratificada em seu componente fixo, variável e mediante pagamentos baseados em ações. As pesquisas internacionais que analisam as determinantes da remuneração dão suporte às estratificações escolhidas, conforme apresentado na Tabela 2.

Na pesquisa, foi considerada no cálculo da remuneração executiva a compensação em reais. Os dados para remuneração foram extraídos do item 13 do FR e foram operacionalizados como segue no Quadro 2. 
Tabela 2 - Estratificação da remuneração executiva

\begin{tabular}{|c|c|c|c|c|}
\hline & $\begin{array}{c}\text { Remuneração } \\
\text { total }\end{array}$ & $\begin{array}{l}\text { Remuneração } \\
\text { fixa }\end{array}$ & $\begin{array}{c}\text { Remuneração } \\
\text { variável }\end{array}$ & $\begin{array}{c}\text { Remuneração } \\
\text { baseada em ações }\end{array}$ \\
\hline Elkinawy e Stater (2011) & $\mathrm{X}$ & $\mathrm{X}$ & & \\
\hline Fernandes (2008) & & $\mathrm{X}$ & $\mathrm{X}$ & \\
\hline Ghosh e Sirmans (2005) & $\mathrm{X}$ & & & \\
\hline Yan $(2015)$ & $\mathrm{X}$ & & & $\mathrm{X}$ \\
\hline Franken (2010) & & & $\mathrm{X}$ & \\
\hline $\begin{array}{l}\text { Lam, McGuinness e } \\
\text { Vieito (2013) }\end{array}$ & $X$ & & & \\
\hline
\end{tabular}

Fonte: Elaborada pelos autores.

Foram retirados, e analisados a parte, os pagamentos baseados em ações da remuneração variável, por considerar que estes acentuam possíveis problemas de conflito de interesses. Este procedimento, também se fudamenta na existência de diversas nomenclaturas utilizadas pelas empresas quando o assunto é pagamento baseado em ações. As empresas, em sua maioria, utilizam nomenclaturas genéricas, tais como: plano baseado em ações, unidades de investimento, performance shares, ações virtuais e free shares.

Quadro 2 - Medidas da Remuneração Executiva.

\begin{tabular}{|l|l|l|l|}
\hline Remuneração Total & lnTotal & $\begin{array}{l}\ln (\text { Remuneração Fixa + Remuneração Variável + } \\
\text { Remuneração Baseada em Ações) }\end{array}$ & $\begin{array}{l}\text { equação } \\
1\end{array}$ \\
\hline Remuneração Fixa & lnFixa & $\begin{array}{l}\ln (\text { Salário ou pró-labore + Benefícios direitos e indiretos + } \\
\text { Participações em comitês + Outros valores fixos) }\end{array}$ & $\begin{array}{l}\text { equação } \\
2\end{array}$ \\
\hline $\begin{array}{l}\text { Remuneração } \\
\text { Variável }\end{array}$ & lnVariável & $\begin{array}{l}\ln (\text { Bônus + Participação de resultados + Participação em } \\
\text { reuniões + Outros valores variáveis + Benefícios pós- } \\
\text { emprego + Benefícios com cessação do cargo }\end{array}$ & $\begin{array}{l}\text { equação } \\
3\end{array}$ \\
\hline $\begin{array}{l}\text { Remuneração } \\
\text { Baseada em Ações }\end{array}$ & lnAções & $\begin{array}{l}\ln (\text { Stock options + Direitos sobre a valorização de ações + } \\
\text { Participação nos lucros e resultados + Ações restritas + } \\
\text { Unidades de investimentos + Phantom stocks + Ações } \\
\text { condicionadas a resultados + Ações virtuais + Matching + } \\
\text { Performance stock units + Restricted stock units })\end{array}$ & \begin{tabular}{l} 
equação \\
\hline
\end{tabular} \\
\hline
\end{tabular}

Fonte: Elaborado pelos autores

Variáveis de interesse: características dos executivos

As variáveis que mensuram as características dos executivos utilizadas na presente pesquisa e os sinais encontrados pelos estudos anteriores são sumarizados na Tabela 3.

Tabela 3 - Estudos que utilizaram as características dos executivos como determinantes da remuneração

\begin{tabular}{lccccc}
\hline & $\begin{array}{c}\text { Quantidade de } \\
\text { Membros }\end{array}$ & $\begin{array}{c}\text { Grau de } \\
\text { Instrução }\end{array}$ & $\begin{array}{c}\text { Presença de } \\
\text { mulheres } \\
\text { executivas }\end{array}$ & $\begin{array}{c}\text { Dualidade de } \\
\text { cargos }\end{array}$ & Independência \\
\cline { 2 - 6 } Ghosh e Sirmans (2005) & $\mathrm{X}+$ & & $\mathrm{X} ?$ & $\mathrm{X}+$ \\
Fernandes (2008) & $\mathrm{X} ?$ & & $\mathrm{X}+$ & $\mathrm{X}+$ & $\mathrm{X}+$ \\
Elkinawy e Stater (2011) & $\mathrm{X}+$ & $\mathrm{X}+$ & $\mathrm{X}-$ & $\mathrm{X}-$ & $\mathrm{X}-$ \\
Yan (2015) & $\mathrm{X}+$ & $\mathrm{X}-$ & & \\
Lam et al. (2013) & & $\mathrm{X}$ & & & \\
\hline
\end{tabular}

Fonte: Elaborada pelos autores.

Nota: a letra X representa a utilização da variável nos estudos selecionados. Os sinais +, -, * e ?, representam que os autores evidenciaram relação positiva, negativa, dúbia ou inexistente, respectivamente, para estas determinantes da remuneração executiva. 
A quantidade de membros (Membros) foi calculada pelo total dos executivos que compõem o Conselho de Administração (CA), Diretoria Estatutária (DE) e Conselho Fiscal (CF). Conselhos maiores estão associados à maior remuneração do CEO (GHOSH; SIRMANS, 2005). Espera-se uma relação positiva entre a variável Membros e a remuneração executiva, tal como evidenciado por Elkinawy e Stater (2011), Ghosh e Sirmans (2005), Lam et al. (2013) e Yan (2015).

O grau de instrução (Instrução) é a média aritmética simples da titulação dos executivos segundo a seguinte escala: $0=$ sem graduação; $1=$ graduação; $2=$ Master of Business Administration (MBA) e/ou pós-graduação; 3 = mestrado; 4 = doutorado; 5 = pós-doutorado. As credenciais acadêmicas têm um impacto indireto e positivo na remuneração executiva. A pesquisa de Lam et al. (2013) suporta esta relação.

A presença de mulheres (Mulheres) é uma variável de contagem calculada pela soma do total de mulheres nos órgãos administrativos (CA, DE e CF). Estudos indicam que as mulheres recebem uma remuneração menor (OAKLEY,2000; WANZENRIED, 2008) e são mais avessas ao risco do que os homens (BARBER; ODEAN, 2001; GRAHAM, HARVEY; PURI, 2013). Considerando que a remuneração fixa é mais conservadora do que os bônus e as opções de ações, espera-se um sinal positivo da variável Mulheres com a remuneração fixa, e uma relação negativa entre a quantidade de mulheres executivas com as remunerações variáveis e por pagamento baseado em ações.

A dualidade de cargos (d.Dual) é capturada por uma variável binária que assume o valor de 1 (um) caso o CEO atue como presidente do conselho e 0 (zero) caso contrário. As pesquisas que relacionam esta variável como determinante da remuneração apresentaram sinal ambíguo (ELKINAWY; STATER, 2011; YAN, 2015)

A independência (d.Eleito) é capturada por uma variável binária que assume o valor de 1 (um) se o conselheiro foi eleito pelo controlador da empresa e 0 (zero) caso contrário. O resultado para esta variável é ambíguo devido aos achados de Elkinawy e Stater (2011), Fernandes (2008) e Ghosh e Sirmans (2005). Caso o sinal da variável d.Eleito seja positivo, indicará que executivos eleitos influenciam positivamente a remuneração executiva. Já se o sinal for negativo, indicará que executivos eleitos têm incentivos para reduzir a compensação executiva.

\section{Variáveis de controle: rentabilidade e identidade do acionista controlador}

Como proxy de rentabilidade foram utilizadas medidas contábeis de desempenho financeiro, sendo: o retorno sobre os ativos (Roa), desvio-padrão do retorno sobre os ativos (SRoa), crescimento da empresa (lnCresc) e $q$ de Tobin (Q). Espera-se uma relação positiva entre as medidas de rentabilidade e a remuneração executiva, tal como evidenciado por Elkinawy e Stater (2011), Ghosh e Sirmans (2005) e Yan (2015).

O Roa é calculado como a razão entre o lucro líquido e o ativo total. A medida SRoa é o desvio-padrão do Roa dos últimos cinco anos. A variável lnCresc é o logaritmo natural da média aritmética do crescimento do valor de mercado das ações para cinco anos anteriores. $\mathrm{O}$ $q$ de Tobin (Q) é o valor de mercado das ações mais as dividas dividido pelo ativo total da empresa.

Como variável de controle foi inserida a identidade do acionista controlador (d.Identidade). Esta é uma variável binária que assume o valor de 1 (um) caso o acionista controlador seja o Estado e 0 (zero) caso contrário. O sinal esperado para esta relação é dúbio devido os resultados encontrados nas pesquisas de Franken (2010), Lam et al. (2013) e Yan (2015). 


\subsection{Modelos e Técnicas de Análise}

Para capturar a relação entre remuneração e características dos executivos estabelecida na literatura foi proposto o seguinte modelo econométrico:

$$
\begin{aligned}
& \text { (lnTotal; lnFixa; lnVariável; lnAções) }
\end{aligned}
$$

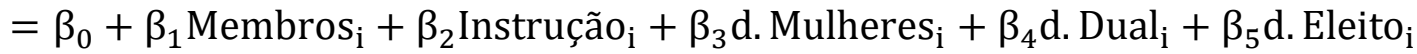

$$
\begin{aligned}
& +\beta_{6} \text { Roa }_{i}+\beta_{7} \text { SRoa }_{i}+\beta_{8} \text { lnCres }_{i}+\beta_{9} Q_{i}+\beta_{10} \text { d. Identidade }_{i} \\
& +\mu_{\mathrm{i}}
\end{aligned}
$$

Inicialmente, foram estimados os parâmetros para a equação 5 com o logaritmo natural do total da remuneração dos executivos (lnTotal). Em um segundo momento, foram reestimados os parâmetros empregando como variável dependente o logaritmo natural do total de remuneração fixa (lnFixa). Posteriormente, os parâmetros foram estimados utilizando o total da remuneração variável dos executivos (lnVariável). Por fim, a equação 5 foi reestimado tendo como variável dependente o total de remuneração baseada em ações (lnAções).

Os modelos foram gerados pela estimativa de Mínimos Quadrados Ordinários (MQO) com erros robustos pela técnica de White (1980). A aplicação da técnica de White objetiva mitigar o problema causado quando os termos de erros das regressões não são homocedásticos.

\section{Análise dos resultados}

\subsection{Análise descritiva}

$\mathrm{Na}$ Tabela 4 são apresentadas as características dos executivos dos órgãos administrativos (CA, DE e CF). Observa-se pelo Painel A que a administração das empresas é formada em primazia por homens, mesmo que a quantidade de mulheres executivas tenha aumentado ao longo dos anos (75, 79, 83 e 105, para os anos de 2013, 2014, 2015 e 2016, respectivamente). A adoção da presença feminina na modelagem estatística objetiva capturar se a remuneração executiva é alterada pela presença de mulheres em cargos da alta direção. De acordo com as características de aversão ao risco evidenciadas na literatura, espera-se que determinados tipos de remuneração sejam influenciados pela presença de mulheres executivas.

Observando as estatísticas para característica "Eleito pelo controlador", proxy para independência do executivo, identifica-se que a maioria dos executivos são eleitos pelo controlador $(71,18 \%, 68,55 \%, 68,21 \%$ e 70,12\%, para os anos de 2013, 2014, 2015 e 2016, respectivamente). A característica de independência pode reduzir o conflito de interesses devido ao maior monitoramento das ações dos agentes externos.

\begin{tabular}{|c|c|c|c|c|c|c|c|c|c|}
\hline \multicolumn{10}{|c|}{ Painel A - Características dos executivos } \\
\hline \multirow[b]{2}{*}{ Composição dos órgãos } & \multirow[b]{2}{*}{ Mulheres } & \multicolumn{2}{|c|}{2013} & \multicolumn{2}{|c|}{2014} & \multicolumn{2}{|c|}{2015} & \multicolumn{2}{|c|}{2016} \\
\hline & & 75 & $7,69 \%$ & 79 & $7,99 \%$ & 83 & $8,51 \%$ & 105 & $10,67 \%$ \\
\hline & Homens & 900 & $92,31 \%$ & 910 & $92,01 \%$ & 892 & $91,49 \%$ & 879 & $89,33 \%$ \\
\hline & & 975 & $100 \%$ & 989 & $100 \%$ & 975 & $100 \%$ & 984 & $100 \%$ \\
\hline \multirow[t]{3}{*}{ Eleito pelo Controlador } & Sim & 694 & $71,18 \%$ & 678 & $68,55 \%$ & 665 & $68,21 \%$ & 690 & $70,12 \%$ \\
\hline & Não & 281 & $28,82 \%$ & 311 & $31,45 \%$ & 310 & $31,79 \%$ & 294 & $29,88 \%$ \\
\hline & & 975 & $100 \%$ & 989 & $100 \%$ & 975 & $100 \%$ & 984 & $100 \%$ \\
\hline \multirow[t]{3}{*}{ Dualidade } & Sim & 32 & $76,19 \%$ & 29 & $69,05 \%$ & 30 & $69,77 \%$ & 31 & $72,09 \%$ \\
\hline & Não & 10 & $23,81 \%$ & 13 & $30,95 \%$ & 13 & $30,23 \%$ & 12 & $27,91 \%$ \\
\hline & & 42 & $100 \%$ & 42 & $100 \%$ & 43 & $100 \%$ & 43 & $100 \%$ \\
\hline
\end{tabular}

Tabela 4 - Características dos órgãos administrativos 


\begin{tabular}{|c|c|c|c|c|c|c|c|c|c|}
\hline \multicolumn{10}{|c|}{ Painel B - Nível educacional dos executivos } \\
\hline \multirow[b]{2}{*}{ Graduação } & \multirow[b]{2}{*}{ Sim } & \multicolumn{2}{|c|}{2013} & \multicolumn{2}{|c|}{2014} & \multicolumn{2}{|c|}{2015} & \multicolumn{2}{|c|}{2016} \\
\hline & & 960 & $98,46 \%$ & 965 & $97,57 \%$ & 954 & $97,85 \%$ & 955 & $97,05 \%$ \\
\hline & Não & 15 & $1,54 \%$ & 24 & $2,43 \%$ & 21 & $2,15 \%$ & 29 & $2,95 \%$ \\
\hline \multirow{4}{*}{ Pós-graduação e/ou $M B A$} & & 975 & $100 \%$ & 989 & $100 \%$ & 975 & $100 \%$ & 984 & $100 \%$ \\
\hline & Sim & 467 & $47,90 \%$ & 470 & $47,52 \%$ & 491 & $50,36 \%$ & 478 & $48,58 \%$ \\
\hline & Não & 508 & $52,10 \%$ & 519 & $52,48 \%$ & 484 & $49,64 \%$ & 506 & $51,42 \%$ \\
\hline & & 975 & $100 \%$ & 989 & $100 \%$ & 975 & $100 \%$ & 984 & $100 \%$ \\
\hline \multirow[t]{3}{*}{ Mestrado } & $\operatorname{Sim}$ & 161 & $16,51 \%$ & 183 & $18,50 \%$ & 173 & $17,74 \%$ & 164 & $16,67 \%$ \\
\hline & Não & 814 & $83,49 \%$ & 806 & $81,50 \%$ & 802 & $82,26 \%$ & 820 & $83,33 \%$ \\
\hline & & 975 & $100 \%$ & 989 & $100 \%$ & 975 & $100 \%$ & 984 & $100 \%$ \\
\hline \multirow[t]{3}{*}{ Doutorado } & $\operatorname{Sim}$ & 27 & $2,77 \%$ & 43 & $4,35 \%$ & 49 & $5,03 \%$ & 51 & $5,18 \%$ \\
\hline & Não & 948 & $97,23 \%$ & 946 & $95,65 \%$ & 926 & $94,97 \%$ & 933 & $94,82 \%$ \\
\hline & & 975 & $100 \%$ & 989 & $100 \%$ & 975 & $100 \%$ & 984 & $100 \%$ \\
\hline \multirow[t]{2}{*}{ Pós-doutorado } & Sim & 12 & $1,23 \%$ & 17 & $1,72 \%$ & 15 & $1,54 \%$ & 15 & $1,52 \%$ \\
\hline & Não & 963 & $98,77 \%$ & 972 & $98,28 \%$ & 960 & $98,46 \%$ & 969 & $98,48 \%$ \\
\hline Total & & 975 & $100 \%$ & 989 & $100 \%$ & 975 & $100 \%$ & 984 & $100 \%$ \\
\hline
\end{tabular}

Fonte: Dados da pesquisa.

A característica de dualidade, CEOs que atuam como presidentes dos conselhos, está presente em 76,19\%, 69,05\%, 69,27\% e 72,09\%, para os anos de 2013, 2014, 2015 e 2016, respectivamente, das empresas analisadas.

No painel B da Tabela 4 é apresentado o nível educacional dos executivos separando os mesmos em graduados, especialistas (pós-graduação e/ou Master in Business Administration), mestres, doutores ou pós-doutores. Ressalva-se que pós-doutorado não é considerado um título, mas sim, uma excelência em determinada área do conhecimento.

Para a primeira característica observa-se que menos de 3\% das empresas para os anos analisados possuem executivos que não são no mínimo graduados. A existência de executivos não graduados pode ser justificada pela presença nos conselhos de fundadores, exclusivamente identificados como empresários.

As demais características que capturam o nível de instrução são assim sumarizadas em relação ao total de executivos e anos analisados: $49 \%$ dos executivos possuem especialização, $17 \%$ têm mestrado, $4 \%$ portam título de doutorado e $2 \%$ são pós-doutores..

$\mathrm{Na}$ Tabela 5 são apresentadas as formas de remunerações dos executivos pertencentes ao CA, DE e CF. Com base no painel A, observa-se aumento da remuneração total do CA ao longo dos anos. O referido aumento diz respeito aos valores em reais da remuneração e em relação à média dos pagamentos. Assim, é possível concluir que ao CA aumentou a remuneração individual dos seus executivos ao longo dos períodos analisados. Sobre os tipos de remuneração, observa-se a predominância da remuneração fixa em face da parcela variável da remuneração. Aquela apresenta variação positiva entre os anos; esta oscila, ora positiva, ora negativamente, sendo que, para todos os anos, o pagamento baseado em ações é o mais representativo entre os tipos de remuneração variável.

Analisando o painel B, que apresenta a remuneração da DE, observa-se aumento da compensação total ao longo dos anos, exceto para o ano de 2016. A redução para este ano está relacionada com a forma de remuneração adotada à diretoria, haja vista que a remuneração variável representa maior parcela na remuneração dos diretores $-60 \%$ do total de remuneração da diretoria é proveniente da remuneração variável, quando analisados todos os anos em conjunto, sendo que a remuneração por meio de bônus e baseadas em ações polarizam os montantes da remuneração variável. 
Tabela 5 - Remuneração dos executivos em reais $(R \$)$

\begin{tabular}{|c|c|c|c|c|c|c|c|c|c|c|c|c|}
\hline \\
\hline & \multicolumn{3}{|c|}{2013} & \multicolumn{3}{|c|}{2014} & \multicolumn{3}{|c|}{2015} & \multicolumn{3}{|c|}{2016} \\
\hline & Média & Soma & Qt & Média & Soma & $\mathrm{Qt}$ & Média & Soma & $\mathrm{Qt}$ & Média & Soma & Qt \\
\hline \multicolumn{13}{|c|}{ Painel A - Remuneração do Conselho de Administração } \\
\hline Remuneração Fixa & 2.743 .880 & 112.499 .093 & & 3.108.254 & 127.438.399 & & 3.158.374 & 135.810.084 & & 3.633.001 & 156.219 .048 & \\
\hline Salário ou pró-labore & 2.253 .419 & 92.390 .195 & 41 & 2.565 .483 & 105.184 .791 & 41 & 2.576 .195 & 110.776 .375 & 43 & 2.885 .414 & 124.072 .810 & 43 \\
\hline Benefícios diretos e indiretos & 102.233 & 920.093 & 9 & 101.984 & 1.223 .808 & 12 & 126.933 & 1.269 .329 & 10 & 145.004 & 1.740 .045 & 12 \\
\hline Participações em comitês & 623.751 & 6.861 .264 & 11 & 561.982 & 6.743 .786 & 12 & 620.610 & 8.067 .933 & 13 & 781.397 & 11.720 .954 & 15 \\
\hline Outros valores fixos & 410.918 & 12.327 .541 & 30 & 476.200 & 14.286 .014 & 30 & 490.514 & 15.696 .447 & 32 & 533.864 & 18.685 .239 & 35 \\
\hline Remuneração Variável & 2.856.352 & 45.701.628 & & 2.493.664 & 42.392.287 & & 2.647 .729 & 42.363.662 & & 2.796 .664 & 50.339 .956 & \\
\hline Bônus & 2.193 .043 & 8.772 .171 & 4 & 2.534 .923 & 15.209 .538 & 6 & 1.551 .395 & 9.308 .369 & 6 & 3.251 .771 & 22.762 .398 & 7 \\
\hline Participação de resultados & 1.695 .483 & 3.390 .966 & 2 & 880.491 & 1.760 .981 & 2 & 1.296 .547 & 3.889 .641 & 3 & 1.196 .229 & 2.392 .458 & 2 \\
\hline Participação em reuniões & 515.484 & 1.030 .967 & 2 & 390.151 & 1.170 .452 & 3 & 790.675 & 2.372 .026 & 3 & 434.299 & 2.605 .795 & 6 \\
\hline Outros valores variáveis & 139.621 & 418.862 & 3 & 381.419 & 1.525 .677 & 4 & 285.715 & 1.714 .288 & 6 & 139.769 & 698.843 & 5 \\
\hline Benefícios Pós-emprego & 129.442 & 647.210 & 5 & 85.698 & 342.791 & 4 & 65.760 & 328.800 & 5 & 103.281 & 413.123 & 4 \\
\hline Benef. Cessação do cargo & 8.275 .900 & 8.275 .900 & 1 & 4.392 .542 & 4.392 .542 & 1 & 4.746 .167 & 4.746 .167 & 1 & & & \\
\hline Rem. Baseada em ações & 3.309 .365 & 23.165 .552 & 7 & 2.570 .044 & 17.990 .307 & 7 & 2.857 .768 & 20.004 .373 & 7 & 3.066 .763 & 21.467 .338 & 7 \\
\hline Remuneração Total & 3.858.554 & 158.200 .721 & & 4.142.212 & 169.830 .686 & & 4.143.575 & 178.173 .746 & & 4.803.698 & 206.559 .003 & \\
\hline \multicolumn{13}{|c|}{ Painel B - Remuneracão da Diretoria Estaturária } \\
\hline Remuneração Fixa & 9.090 .990 & 372.730.570 & & 10.395 .951 & 426.233.995 & & 10.280 .675 & 431.788.350 & & 10.736.049 & 461.650 .100 & \\
\hline Salário ou pró-labore & 6.813 .127 & 279.338 .216 & 41 & 8.025 .082 & 329.028 .380 & 41 & 7.802 .700 & 327.713 .381 & 42 & 8.065 .419 & 346.813 .027 & 43 \\
\hline Benefícios diretos e indiretos & 1.071 .501 & 38.574 .046 & 36 & 1.078 .581 & 39.907 .510 & 37 & 1.179 .131 & 43.627 .841 & 37 & 1.069 .588 & 40.644 .350 & 38 \\
\hline Outros valores fixos & 1.713 .072 & 54.818 .307 & 32 & 1.685 .238 & 57.298 .104 & 34 & 1.831 .731 & 60.447 .128 & 33 & 1.854 .818 & 74.192 .722 & 40 \\
\hline Remuneração Variável & 12.643.445 & 505.737 .816 & & 15.903 .433 & 636.137 .323 & & 18.310 .730 & 750.739 .910 & & 15.266 .854 & 641.207 .889 & \\
\hline Bônus & 7.085 .224 & 141.704 .487 & 20 & 9.110 .089 & 209.532 .038 & 23 & 10.148 .365 & 223.264 .033 & 22 & 8.358 .900 & 183.895 .804 & 22 \\
\hline Participação de resultados & 6.579 .595 & 144.751 .094 & 22 & 7.532 .123 & 158.174 .593 & 21 & 8.496 .825 & 161.439 .669 & 19 & 6.295 .836 & 125.916 .714 & 20 \\
\hline Outros valores variáveis & 1.540 .314 & 21.564 .399 & 14 & 1.827 .821 & 29.245 .142 & 16 & 3.049 .102 & 48.785 .633 & 16 & 4.257 .026 & 76.626 .467 & 18 \\
\hline Benefícios Pós-emprego & 523.698 & 7.855 .463 & 15 & 562.788 & 8.441 .825 & 15 & 506.370 & 8.608 .290 & 17 & 581.558 & 12.212 .727 & 21 \\
\hline Benef. Cessação do cargo & 1.419 .705 & 5.678 .821 & 4 & 13.467 .672 & 26.935 .345 & 2 & 16.672 .130 & 83.360 .649 & 5 & 9.078 .860 & 63.552 .017 & 7 \\
\hline Rem. Baseada em ações & 7.674 .315 & 184.183 .552 & 24 & 7.548 .459 & 203.808 .381 & 27 & 8.045 .773 & 225.281 .637 & 28 & 6.172 .557 & 179.004 .159 & 29 \\
\hline Remuneração Total & 21.426.058 & 878.468.386 & & 25.911.496 & 1.062.371.318 & & 28.155.435 & 1.182.528.261 & & 25.647 .860 & 1.102.857.988 & \\
\hline \multicolumn{13}{|c|}{ Painel C - Remuneração do Conselho Fiscal } \\
\hline Remuneração Fixa (Total) & 522.345 & 18.804 .424 & & 570.083 & 19.952 .903 & & 628.876 & 21.381 .793 & & 677.130 & 23.699 .544 & \\
\hline Salário ou pró-labore & 447.236 & 16.100 .486 & 36 & 485.169 & 16.980 .905 & 35 & 532.772 & 18.114 .245 & 34 & 579.018 & 20.265 .614 & 35 \\
\hline Benefícios diretos e indiretos & 62.666 & 250.664 & 4 & 53.265 & 372.855 & 7 & 53.492 & 267.462 & 5 & 66.202 & 264.807 & 4 \\
\hline Outros valores fixos & 87.617 & 2.453 .274 & 28 & 99.967 & 2.599 .143 & 26 & 107.146 & 3.000 .087 & 28 & 105.637 & 3.169 .124 & 30 \\
\hline
\end{tabular}

Fonte: Dados da pesquisa. 
Sociedade, Contabilidade e Gestão, Rio de Janeiro, v. 14, n. 1, jan./abr., 2019

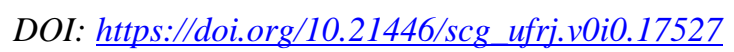

Tabela 6 - Correlação de Pearson e Spearman

\begin{tabular}{|c|c|c|c|c|c|c|c|c|c|c|c|c|c|c|}
\hline & 1 & 2 & 3 & 4 & 5 & 6 & 7 & 8 & 9 & 10 & 11 & 12 & 13 & 14 \\
\hline \multirow[t]{2}{*}{ 1.lnTotal } & & 0,698 & 0,838 & 0,454 & 0,467 & 0,088 & 0,219 & $-0,472$ & 0,005 & 0,089 & 0,005 & 0,421 & $-0,001$ & - \\
\hline & & $0,000 * * *$ & $0,000 * * *$ & $0,000 * * *$ & $0,000 * * *$ & 0,377 & $0,026 * *$ & $0,000 * * *$ & 0,692 & 0,370 & 0,958 & $0,000 * * *$ & 0,989 & - \\
\hline \multirow[t]{2}{*}{ 2.InFixa } & 0,843 & & 0,507 & $-0,021$ & 0,598 & $-0,056$ & 0,350 & $-0,373$ & 0,189 & $-0,135$ & $-0,040$ & 0,485 & 0,211 & - \\
\hline & $0,000 * * *$ & & $0,000 * * *$ & 0,832 & $0,000 * * *$ & 0,576 & $0,000 * * *$ & $0,000 * * *$ & $0,056^{*}$ & 0,174 & 0,685 & $0,000 * * *$ & $0,033 * *$ & - \\
\hline \multirow[t]{2}{*}{ 3.lnVariável } & 0,869 & 0,641 & & 0,225 & 0,341 & 0,059 & 0,129 & $-0,449$ & $-0,052$ & 0,031 & $-0,010$ & 0,268 & 0,074 & - \\
\hline & $0,000 * * *$ & $0,000 * * *$ & & $0,022 * *$ & $0,000 * * *$ & 0,554 & 0,195 & $0,000 * * *$ & 0,602 & 0,754 & 0,918 & $0,006 * * *$ & 0,458 & - \\
\hline \multirow[t]{2}{*}{ 4.lnAções } & 0,451 & 0,021 & 0,172 & & 0,080 & 0,020 & 0,061 & $-0,202$ & $-0,295$ & 0,323 & $-0,096$ & 0,058 & $-0,187$ & - \\
\hline & $0,000 * * *$ & 0,830 & $0,082 *$ & & 0,419 & 0,841 & 0,543 & $0,040 * *$ & $0,003 * * *$ & $0,001 * * *$ & 0,337 & 0,560 & $0,059 *$ & - \\
\hline \multirow[t]{2}{*}{ 5.Membros } & 0,203 & 0,352 & 0,189 & $-0,001$ & & $-0,202$ & 0,407 & $-0,364$ & 0,437 & $-0,180$ & 0,112 & 0,374 & 0,124 & - \\
\hline & $0,008 * * *$ & $0,000 * * *$ & $0,015 * *$ & 0,994 & & $0,041 * *$ & $0,000 * * *$ & $0,000 * * *$ & $0,000 * * *$ & $0,069 *$ & 0,261 & $0,000 * * *$ & 0,212 & - \\
\hline \multirow[t]{2}{*}{ 6.Instrução } & $-0,213$ & $-0,161$ & $-0,203$ & $-0,024$ & $-0,147$ & & $-0,230$ & 0,031 & 0,060 & $-0,180$ & 0,315 & 0,088 & $-0,057$ & - \\
\hline & $0,005 * * *$ & $0,036 * *$ & $0,009 * * *$ & 0,809 & $0,055^{*}$ & & $0,020 * *$ & 0,759 & 0,544 & $0,068 *$ & $0,001 * * *$ & 0,379 & 0,568 & - \\
\hline \multirow[t]{2}{*}{ 7.Mulheres } & 0,187 & 0,317 & 0,120 & $-0,034$ & 0,552 & $-0,188$ & & $-0,071$ & 0,130 & 0,019 & 0,055 & $-0,085$ & $-0,016$ & - \\
\hline & $0,015 * *$ & $0,000 * * *$ & 0,127 & 0,731 & $0,000 * * *$ & 0,014 & & 0,476 & 0,192 & 0,852 & 0,578 & 0,391 & 0,873 & - \\
\hline \multirow[t]{2}{*}{ 8.d.Dual } & $-0,342$ & $-0,293$ & $-0,379$ & $-0,220$ & $-0,286$ & 0,059 & $-0,206$ & & $-0,037$ & $-0,067$ & $-0,307$ & $-0,114$ & $-0,202$ & - \\
\hline & $0,000 * * *$ & $0,000 * * *$ & $0,000 * * *$ & $0,024 * *$ & $0,000 * * *$ & 0,446 & $0,007 * * *$ & & 0,714 & 0,503 & $0,002 * * *$ & 0,254 & $0,041 * *$ & - \\
\hline \multirow[t]{2}{*}{ 9.d.Eleito } & $-0,053$ & 0,037 & $-0,006$ & $-0,245$ & 0,597 & 0,053 & 0,319 & $-0,071$ & & $-0,301$ & 0,356 & 0,235 & 0,209 & - \\
\hline & 0,493 & 0,633 & 0,935 & $0,012 * *$ & $0,000 * * *$ & 0,491 & $0,000 * * *$ & 0,358 & & $0,002 * * *$ & $0,000 * * *$ & $0,017 * *$ & $0,035 * *$ & - \\
\hline \multirow[t]{2}{*}{ 10.Roa } & 0,193 & 0,106 & 0,155 & 0,405 & 0,004 & $-0,171$ & $-0,088$ & $-0,020$ & $-0,074$ & & $-0,018$ & $-0,031$ & $-0,537$ & - \\
\hline & $0,012 * *$ & 0,171 & $0,048 * *$ & $0,000 * * *$ & 0,962 & 0,026 & 0,256 & 0,792 & 0,336 & & 0,856 & 0,759 & $0,000 * * *$ & - \\
\hline \multirow[t]{2}{*}{ 11.Sroa } & $-0,044$ & $-0,104$ & $-0,003$ & $-0,115$ & 0,073 & 0,049 & 0,104 & $-0,277$ & 0,132 & $-0,415$ & & $-0,003$ & 0,176 & - \\
\hline & 0,574 & 0,179 & 0,974 & 0,243 & 0,345 & 0,524 & 0,179 & $0,000 * * *$ & $0,087 *$ & $0,000 * * *$ & & 0,974 & $0,076^{*}$ & - \\
\hline \multirow[t]{2}{*}{ 12.lnCresc } & 0,326 & 0,401 & 0,136 & 0,164 & 0,348 & 0,098 & 0,056 & $-0,116$ & 0,235 & 0,085 & 0,073 & & 0,121 & - \\
\hline & $0,000 * * *$ & $0,000 * * *$ & $0,084 *$ & $0,095^{*}$ & $0,000 * * *$ & 0,203 & 0,466 & 0,133 & $0,002 * * *$ & 0,269 & 0,346 & & 0,225 & - \\
\hline \multirow[t]{2}{*}{ 13.Q } & $-0,005$ & 0,141 & $-0,004$ & $-0,116$ & 0,207 & 0,134 & 0,188 & $-0,043$ & 0,272 & $-0,346$ & 0,074 & 0,125 & & - \\
\hline & 0,952 & $0,067 *$ & 0,962 & 0,239 & $0,007 * * *$ & 0,082 & 0,014 & 0,578 & $0,000 * * *$ & $0,000 * * *$ & 0,335 & 0,104 & & - \\
\hline \multirow[t]{2}{*}{ 14.d.Identidade } & $-0,358$ & $-0,117$ & $-0,489$ & - & 0,203 & 0,228 & 0,121 & 0,221 & 0,093 & $-0,081$ & $-0,022$ & 0,177 & 0,218 & \\
\hline & $0,000 * * *$ & 0,129 & $0,000 * * *$ & - & $0,008 * * *$ & 0,003 & 0,117 & $0,004 * * *$ & 0,230 & 0,292 & 0,775 & $0,021 * *$ & $0,004 * * *$ & \\
\hline
\end{tabular}

Fonte: Dados da pesquisa. 
No painel C é mostrada a compensação do $\mathrm{CF}$, que apenas utiliza remuneração fixa como forma de compensação. A remuneração para esses conselheiros aumentou ao longo dos anos, tendo como predominante a compensação mediante salários ou pró-labores $-85 \%$ da remuneração total para todos os anos analisados é proveniente dessa forma de remuneração.

No geral, a remuneração para o CA e CF é mais conservadora, devido à predominância da parcela fixa da remuneração para os conselheiros administrativos, e a inexistência de remuneração variável para os conselheiros fiscais. Contrariamente, os diretores executivos possuem um plano de remuneração mais sucetível a oscilações do mercado acionário, pois a remuneração variável desses conselheiros é proporcionalmente maior do que sua parcela fixa.

Na Tabela 6 são apresentados os resultados da correlação de Pearson, no eixo inferior, e de Spearman, no eixo superior. Analisando as variáveis de interesse, é possível verificar uma relação significativa e positiva do total de executivos e a remuneração total, fixa e variável. Esta relação sugere aumento da remuneração quando os órgãos administrativos são compostos por mais executivos. Contrário ao encontrado na pesquisa de Lam et al. (2013), o grau de instrução apresenta relação negativa com a remuneração total, fixa e variável. Para presença de mulheres nos conselhos, é evidenciado uma relação positiva e significativa com a remuneração total e fixa.

Este achado sugere que a presença de mulheres torna os planos de remuneração mais conservadores. A dualidade apresenta relação negativa com a remuneração total, fixa, variável e baseada em ações. Estas evidências indicam que o CEO como presidente do conselho reduz a remuneração dos executivos. A falta de independência dos executivos, capturada pela variável d.Eleito, está positivamente relacionada com a remuneração fixa e negativamente com a remuneração baseado em ações.

Analisando as variáveis de controle, as medidas de rentabilidade Roa, $\operatorname{lnCresc}$ e Q apresentam relação positiva com os tipos de remuneração. Isso indica que a remuneração executiva no geral é impactada pelo desempenho da empresa. Já a variável de controle d.Identidade está negativamente relacionada com a remuneração total e variável.

No geral, os coeficientes das correlações entre as variáveis dependentes e as variáveis independentes estão em parâmetros aceitáveis (menor do que 0,8 conforme Gujarati e Porter (2011)). Os coeficientes também não são considerados altos quando comparadas as relações entre as variáveis independentes, indicando não haver problemas de multicolinearidade dos dados.

Os resultados da parte descritiva da pesquisa são comparáveis com os estudos internacionais. Yermack (1995), com base em uma amostra composta pelas 792 maiores empresas norte americanas, evidenciou que as opções de ações passaram de $20 \%$ em 1984 para 35\% em 1990 e 30\% em 1991. Murphy (2002) mostrou que na década de 1990 a compensação média quase que triplicou, mostrando aumento expressivo da remuneração baseada em opções de ações que passou de 27\% (1992) para 51\% (2000), enquanto o salário fixo mostrou uma redução de 35\% (1992) para 18\% (2000). Corroborando com esta evidência, Balsam (2002) verificou que a média da remuneração total teve aumento de 401\% (1992-2000), opção de ações obtiveram um aumento de 21\% (1992) para 42\% (2000), salário fixo passou de 47\% (1992) para $20 \%$ (2000), quando analisadas as empresas contidas nas bases de dados S\&P500, S\&P MidCap400, e S\&P SamllCap600.

Em pesquisa realizada por Kolb (2012) com os CEOs da S\&P 500, entre 1992 a 2010 , foi evidenciado que a média da compensação baseada em opções de ações teve um aumento de U\$ 250.000 (1992) para quase U\$ 10 milhões (2000), considerado o auge da "bolha" do setor tecnológico. Em 1992, a compensação dos executivos era composta por quase $30 \%$ de opções de ações, passando para $70 \%$ em 2000, e $20 \%$ em 2010. Em contrapartida, as ações restritas se tornaram mais populares, crescendo de $20 \%$ para $80 \%$ no período. 
Frydman e Jenter (2010) identificaram que as compensações por opções representavam $20 \%$ da remuneração dos CEOs em 1992, aumentando para $49 \%$ em 1999, e reduzindo para $25 \%$ em 2008. Enquanto a remuneração por ações restritas passou a ser mais popular em 2006, ultrapassando o valor pago pelas opções de ações. Em contrapartida a remuneração fixa (salários), passou de 42\% em 1992 para 17\% em 2008.

Em geral, os resultados transcritos indicam que as empresas, ao longo dos anos, optaram pela mudança da compensação mediante pagamento baseado em ações de stock options (SO) para restricted options (RS).

Na presente pesquisa, evidenciou-se que o pagamento baseado em ação possui algumas modalidades. Na análise de dados observou-se que, nos anos de 2016 e 2015, das 43 empresas que compõem a amostra, 29 remuneraram os executivos com base em ações em 2016 e 28 em 2015. Dessas empresas que possuíram algum tipo de remuneração baseada em ação e que divulgaram de forma explícita no FR em 2016, 23 empresas informaram que remuneravam através de SO, seguido por 6 empresas que comunicaram utilizar RS. Para 2015, 22 empresas informaram utilizar SO, enquanto 6 utilizaram RS. Para os anos de 2014 e 2013, 27 e 24 empresas remuneraram os executivos com base em ações, respectivamente. Dessas empresas que possuíram pagamentos baseados em ações e que foram divulgados de forma explícita no FR em 2014, 21 informaram utilizar SO, enquanto 3 utilizaram RS. Para 2013, 17 informaram utilizar SO, enquanto 2 utilizaram RS.

Os achados nacionais indicam o oposto dos internacionais, dado que, pela amostra, as empresas fazem uso quase que exclusivamente das SO. Para Kolb (2012), as opções de ações são benéficas aos executivos, incentivando os mesmos a maximizarem os resultados das empresas. Ainda segundo o autor, quantidades elevadas de ações restritas nos planos de remuneração, podem incentivar os executivos a tomarem decisões mais conservadoras. Para Lipman e Hall (2008), esta cautela na tomada de decisões está relacionada à associação do pagamento mediante ações restritas às metas de desempenho das empresas.

A diferença nos resultados encontrados nesta pesquisa e nos estudos internacionais indica que o Brasil apresenta característica menos conservadora quando da forma de remuneração executiva. Este modelo aparenta ser vantajoso para as empresas, porém nem sempre o mesmo será para os executivos, pois, segundo Kolb (2012), a remuneração através das opções de ações pode ser ineficiente, devido o fato de os executivos terem que desembolsar valores monetários para exercer o direito da opção de ação.

\subsection{Análise econométrica}

Na Tabela 7 são apresentados os resultados das estimações da equação 5, tendo como variáveis dependentes a remuneração total e os tipos de remuneração. As interpretações dos parâmetros dos modelos estão condicionadas às variáveis dependentes. A remuneração fixa captura o efeito conservador da remuneração, assim, a interpretação dos coeficientes estimados deve ter como prerrogativa que a compensação fixa é mais conservadora. O contrário ocorre quando da interpretação das remunerações variáveis (lnVariável) e baseada em ações (lnAções), um vez que estas remunerações estão relacionadas com maior risco e volatividade do mercado acionário.

As características dos executivos apresentaram significância estatística com as medidas de remuneração. Especificamente, a quantidade de executivos apresenta relação positiva com o total de remuneração, a parcela fixa da compensação e a parcela variável (Membros: coef. $0,015, \mathrm{p}<0,10$; coef. $0,019, \mathrm{p}<0,01$; e coef. $0,034, \mathrm{p}<0,01$, respectivamente). Isso significa que conselhos maiores têm impacto direto na remuneração executiva, independentemente do tipo da mesma. Deste modo, há indícios de que as decisões de remuneração são mais propensas a serem influenciadas quando os órgãos administrativos são maiores. Essa evidência está de 
acordo com os achados de Elkinawy e Stater (2011), Ghosh e Sirmans (2005), Lam et al. (2013) e Yan (2015).

Tabela 7 - Determinantes da remuneração executiva

\begin{tabular}{|c|c|c|c|c|c|}
\hline \multirow{2}{*}{\multicolumn{2}{|c|}{ Variáveis de Interesse }} & $\ln$ Total $_{\mathrm{i}}$ & $\operatorname{lnFixa}_{\mathrm{i}}$ & $\ln$ Variável ${ }_{i}$ & $\ln A c ̧ o ̃ e s_{i}$ \\
\hline & & & & & \\
\hline \multirow{2}{*}{\multicolumn{2}{|c|}{ Membros $_{i}$}} & {$[0,015]$} & {$[0,019]$} & {$[0,034](0,01)$} & {$[0,013](0,02)$} \\
\hline & & $1,83 *$ & $2,69 * * *$ & $2,88 * * *$ & 0,75 \\
\hline \multirow{2}{*}{\multicolumn{2}{|c|}{ Instrução $_{i}$}} & {$[-0,064]$} & {$[-0,047]$} & {$[-0,025]$} & {$[0,152](0,12)$} \\
\hline & & $-1,00$ & $-0,90$ & 0,76 & 1,24 \\
\hline \multirow{2}{*}{\multicolumn{2}{|c|}{ d.Mulheres ${ }_{i}$}} & {$[0,081]$} & {$[0,100]$} & {$[0,050](0,04)$} & {$[0,022](0,06)$} \\
\hline & & $2,63 * * *$ & $3,56 * * *$ & 1,16 & 0,36 \\
\hline \multirow{2}{*}{\multicolumn{2}{|c|}{ d.Dual ${ }_{i}$}} & {$[-0,189]$} & {$[-0,154]$} & {$[-0,236]$} & {$[-0,218]$} \\
\hline & & $-2,10 * *$ & $-1,70 *$ & $-1,99 * *$ & $-1,24$ \\
\hline \multirow{2}{*}{\multicolumn{2}{|c|}{ d.Eleito ${ }_{i}$}} & {$[-0,024]$} & {$[-0,021]$} & {$[-0,025]$} & {$[-0,030]$} \\
\hline & & $-4,17 * * *$ & $-4,47 * * *$ & $-3,20 * * *$ & $-2,86 * * *$ \\
\hline \multicolumn{6}{|c|}{ Variáveis de Controle } \\
\hline \multirow{2}{*}{\multicolumn{2}{|c|}{$\operatorname{Roa}_{\mathrm{i}}$}} & {$[1,652]$} & {$[0,175]$} & {$[2,387](1,59)$} & {$[8,211] \quad(2,46)$} \\
\hline & & 1,38 & 0,17 & 1,50 & $3,33 * * *$ \\
\hline \multirow{2}{*}{\multicolumn{2}{|c|}{ SRoa $_{i}$}} & {$[-2,934]$} & {$[-6,350]$} & {$[0,186](3,76)$} & {$[-5,648]$} \\
\hline & & $-0,80$ & $-2,08 * *$ & 0,05 & $-0,92$ \\
\hline \multirow{2}{*}{\multicolumn{2}{|c|}{$\operatorname{lnCresc}_{i}$}} & {$[0,321]$} & {$[0,304]$} & {$[0,225](0,07)$} & {$[0,148](0,12)$} \\
\hline & & $6,94 * * *$ & $6,68 * * *$ & $3,07 * * *$ & 1,27 \\
\hline \multirow{2}{*}{\multicolumn{2}{|c|}{$\mathrm{Q}_{\mathrm{i}}$}} & {$[0,404]$} & {$[0,552]$} & {$[0,799](0,48)$} & {$[0,982](0,85)$} \\
\hline & & 1,17 & $1,84^{*}$ & $1,67^{*}$ & 1,16 \\
\hline \multirow{2}{*}{\multicolumn{2}{|c|}{ d.Identidade $_{i}$}} & {$[-1,082]$} & {$[-0,523]$} & {$[-2,202]$} & - \\
\hline & & $-7,42 * * *$ & $-3,42 * * *$ & $-10,28 * * *$ & - \\
\hline \multirow{2}{*}{\multicolumn{2}{|c|}{ Constante $_{\mathrm{i}}$}} & {$[9,616]$} & {$[9,076]$} & {$[10,059]$} & {$[11,408]$} \\
\hline & & $9,57 * * *$ & $8,76 * * *$ & $6,26 * * *$ & $4,45 * * *$ \\
\hline \multicolumn{2}{|c|}{ Observações } & 170 & 170 & 164 & 105 \\
\hline$R^{2}$ & & 0,44 & 0,42 & 0,45 & 0,28 \\
\hline \multicolumn{6}{|c|}{ Teste de multicolinearidade } \\
\hline \multicolumn{6}{|c|}{ Teste de normalidade } \\
\hline \multicolumn{2}{|c|}{ Skewness/Kurtosis } & {$[4,920] \quad 0,09 *$} & {$[7,760]$} & {$[3,570] \quad 0,17$} & {$[1,670] \quad 0,43$} \\
\hline \multicolumn{2}{|c|}{ Jarque-Bera } & {$[4,448] \quad 0,11$} & {$[8,486]$} & {$[3,507] \quad 0,17$} & {$[1,679] \quad 0,43$} \\
\hline \multicolumn{6}{|c|}{ Teste de autocorrelação } \\
\hline \multirow{2}{*}{\multicolumn{2}{|c|}{$\begin{array}{l}\text { Durbin-Watson } \\
\text { Teste de endogeneidade }\end{array}$}} & 2,106 & 1,999 & 2,025 & 1,765 \\
\hline & & & & & \\
\hline \multirow{2}{*}{\multicolumn{2}{|c|}{$\begin{array}{ll} & \text { Resíduo de } \\
\text { Hausman } & \text { Roa }_{\mathrm{i}} \\
& \text { Resíduo de } \mathrm{Q}_{\mathrm{i}}\end{array}$}} & 0,397 & $0,063^{*}$ & 0,582 & 0,611 \\
\hline & & 0,413 & 0,302 & 0,582 & $0,023 * *$ \\
\hline \multicolumn{6}{|c|}{ Teste de especificação do modelo } \\
\hline
\end{tabular}

Fonte: Elaborada pelos autores.

Nota: *,**,*** indica a significância estatística nos níveis de $0,10,0,05$ e 0,01 , respectivamente. Variáveis definidas na seção 3.2. Nas estimativas dos modelos econométricos os valores em colchetes representam os coeficientes, os valores em parênteses representam os erros-padrões robustos pela técnica de White (1980) e os valores abaixo destes representam a estatística $t$. Nas estimativas dos testes de normalidade os números em colchetes representam os valores do teste e os a sua frente a estatística do referido teste. $R^{2}$ representa o poder estatístico do modelo de forma global. Vif mínimo e vif máximo representam os valores mínimos e máximos do teste variance inflation factor, respectivamente. Segundo Gujarati e Porter (2011) quanto maior for o valor vif, superior a 10, há variáveis com alta colinearidade. Skewness/Kurtosis e Jarque-Bera testam a normalidade dos resíduos da regressão, tendo como $\mathrm{H}_{0}$ : normalidade. Os testes de normalidade indicaram que os resíduos dos modelos com as variáveis dependentes $\operatorname{lnTotal}$, $\ln$ Variável e $\ln$ Ações apresentam distribuição normal. DurbinWatson testa a hipótese de aleatoriedade e independência dos termos de erro, tendo como $\mathrm{H}_{0}$ : nenhuma autocorrelação seja positiva ou negativa. A interpretação do teste de Durbin-Watson seguiu a regra de rejeição: $d_{u}<$ estatística do teste $<4-d_{u}$. Pelo teste não há autocorrelação positiva ou negativa para os modelos com variável dependente $\operatorname{lnT}$ Total, lnFixa e lnVariável. Já para o modelo com variável dependente lnAções, a estatística do teste se encontra na área de não decisão. Hausman verifica se um regressor está correlacionado 
ao termo de erro, sendo $\mathrm{H}_{0}$ : ausência de endogeneidade. Para realizar o teste foi considerado o desempenho global (Roa e Q) como possíveis regressores correlacionados com o termo de erro. O teste de endogeneidade seguiu o sugerido por Gujarati e Porter (2011, p. 697), sendo considerado nos modelos com o desempenho global a variável independente logaritmo natural do ativo total das empresas, por esta representar determinante do desempenho. Com base no teste de Hausman verifica-se presença de endogeneidade nos modelos com as variáveis dependentes $\operatorname{lnFixa}($ Roa, $\mathrm{p}<0,10)$ e $\ln$ Ações $(\mathrm{Q}, \mathrm{p}<0,05)$. Visto que a endogeneidade não foi observada em todos os modelos e com todas as variáveis testadas, e a fraca significância estatística para o teste com a variável Roa, os testes não invalidam a pesquisa, servindo de parâmetro para interpretações cautelosas dos resultados quando dos modelos com as variáveis dependentes lnFixa e lnAções. Ramsey RESET avalia a existência de erros de especificação do modelo referente à possível omissão de variáveis relevantes, sendo $\mathrm{H}_{0}$ : as variáveis omitidas não são significantes. A estatística do teste indica que os modelos foram corretamente especificados quanto às variáveis selecionadas - possível fonte de endogeneidade.

A presença de mulheres executivas impacta positivamente a remuneração total e sua parcela fixa (d.Mulheres: coef. $0,081, \mathrm{p}<0,01$; coef. $0,100, \mathrm{p}<0,01$, respectivamente). Tendo em vista que a parcela fixa da compensação executiva é considerada mais conservadora, o achado indica que a presença de mulheres conselheiras aumenta esse tipo de remuneração. As descobertas da pesquisa corroboram ao discutido na literatura de que as mulheres são mais avessas ao risco (BARBER; ODEAN, 2001; GRAHAM; HARVEY; PURI, 2013), preferindo assim, planos de remuneração mais conservadores.

A dualidade de cargos (d.Dual) é negativa e estatisticamente significante com as variáveis dependentes, exceto a dualidade para remuneração baseada em ações (lnAções). Os achados indicam que a presença do CEO como presidente do conselho reduz a compensação executiva, tanto em sua parcela fixa quanto em sua parcela variável. Esses resultados são condizentes com a pesquisa de Yan (2015).

A proxy para independência do conselheiro (d.Eleito) está negativamente relacionada com a totalidade e os tipos de remuneração. Os achados indicam que a falta de independência reduz a remuneração executiva. Todavia, devido à forma de operacionalização da variável, os achados devem ser interpretados com cautela. As evidências encontradas são contrárias à ideia de que uma maior proporção de membros independentes do conselho implica em maior monitoramento (FERNANDES, 2008), acarretando na redução do oportunismo gerencial por meio da otimização dos contratos de compensação (CONYON; HE, 2011).

Em relação as variáveis de controle, consoante com os achados de Elkinawy e Stater (2011), Ghosh e Sirmans (2005) e Yan (2015), as variáveis de rentabilidade Roa, lnCresc e Q estão significativamente relacionadas com as medidas de remuneração executiva. Especificamente, o coeficiente para a medida de desempenho financeiro global Roa é significativo para explicar a remuneração baseada em ações (coef. 8,211, p <0,01). Os achados para o desvio-padrão do Roa (SRoa) são significativos e negativos quando relacionado à remuneração fixa (coef. $-6,350, \mathrm{p}<0,05$ ). A medida de crescimento do valor de mercados das ações (lnCresc) apresentou-se positivamente relacionada com o total de remuneração e sua parcela fixa e variável (coef. 0,321, p < 0,01; coef. 0,304, p <0,01; e coef. 0,225, p < 0,01, respectivamente). A medida de desempenho finaceiro global, o $q$ de Tobin (Q) apresentou relação positiva com a remuneração executiva fixa e variável (coef. 0,552, p < 0,10 e coef. $0,799, \mathrm{p}<0,10$, respectivamente).

Em análise conjunta, os resultados indicam que empresas com maior desempenho financeiro compõem planos de remuneração com características que se propõem a ser vantajosas aos executivos. $\mathrm{O}$ impacto negativo da dispersão do desempenho na remuneração indica que os planos de remuneração sofrem impacto da oscilação do desempenho. Não obstante, os resultados para as medidas de rentabilidade devem ser interpretados com cautela, limitando-se a amostra selecionada no estudo, devido à falta de significância estatística das variáveis para todas as especificações da equação 5, bem como ao baixo valor da significância estatística de algumas variáveis. 
A proxy que captura a identidade do controlador da empresa (d.Identidade) apresentou relação estatística e negativa quando explicativa da remuneração total, fixa e variável (coef. $1,082, \mathrm{p}<0,01$; coef. $-0,523, \mathrm{p}<0,01$; e coef. $-2,202, \mathrm{p}<0,01$, respectivamente). Assim, os executivos de empresas com controle estatal podem receber recompensas menores devido ao maior monitoramento por parte dos stakeholders e shareholders envolvidos nessas organizações.

\section{Conclusão}

O presente trabalho objetivou mapear os tipos, bem como identificar os determinantes da remuneração dos executivos que compõem o CA, a DE e o CF das empresas com ações negociadas no mercado acionário brasileiro. Para operacionalizar a pesquisa foram selecionadas as empresas que integravam o índice Ibovespa de 2017, sendo que a amostra final culminou em 170 empresas/ano para o período de 2013 a 2016.

Sobre a remuneração por órgãos administrativos, observou-se que o CA e o CF possuem planos de remuneração com maior parcela de remuneração fixa, já a DE tem remuneração composta em sua maioria por pagamentos variáveis e remuneração baseada em ações.

Com relação aos tipos de compensação, destaca-se que a remuneração baseada em ação, como um todo, apresentou variação positiva nos três primeiros anos analisados, revertendo essa tendência em 2016. Uma possível explicação para esta oscilação é a atual situação econômica do mercado brasileiro, que distancia as empresas de suas metas traçadas. Em relação à remuneração fixa, observou aumento no período analisado, sugerindo conservadorismo por parte dos gestores. As empresas utilizaram predominantemente as $\mathrm{SO}$ como pagamento baseado em ações, ao contrário das empresas norte-americanas que passaram a remunerar em maior parcela com RS. Isso sugere aumento do conservadorismo, dado que as RS maximizam o mesmo (KOLB, 2012).

Os achados para os determinantes da remuneração executiva indicam que conselhos maiores podem influenciar nos planos de compensação, tornando os mesmos mais vantajosos, acentuando, assim, possível conflito de interesses. A presença de mulheres conselheiras (167 no CA, 72 na DE e 103 no CF, no total) torna os planos de remuneração mais conservadores, corroborando com o disciplinado por Barber e Odean (2001) e Graham et al. (2013) que mulheres executivas são mais avessas ao risco do que os homens. Os CEOs quando presidentes dos conselhos podem atenuar conflitos de interesse agindo como agentes monitores da remuneração executiva. A falta de independência reduz o montante da compensação dos executivos. Este achado é contrário ao teorizado, de que uma maior proporção de conselheiros independentes acarreta maior monitoramento dos planos remuneratórios.

No geral, conclui-se que: conselhos maiores influenciam positivamente o plano de remuneração executiva; conselheiras mulheres possuem uma remuneração mais conservadora - baseada em elementos fixos; CEOs atuando como presidente do conselho tendem a reduzir a remuneração executiva; empresas em que os conselheiros são eleitos pelo controlador apresentam maiores planos de remuneração; a rentabilidade está positivamente relacionada com a remuneração e; a compensação executiva é menor em empresas controladas pelo Estado. Ressalta-se que a falta de significância da medida de nível educacional indica que no Brasil os executivos não são exclusivamente remunerados com base em seu grau de instrução, mas sim, em outros fatores, tais como experiência profissional.

Os resultados estendem a literatura que discorre sobre planos de remuneração. Especificamente, introduzem a ideia de conservadorismo remuneratório ao classificar a remuneração por seus tipos. Deste modo, os resultados são relevantes e diferenciam-se dos demais por considerar o pagamento baseados em ações como componente variável que pode maximizar o conflito de agência. Outra característica singular da pesquisa é a relação da 
presença feminina por tipo de remuneração, haja vista que a teoria disciplina que as mulheres têm como característica a aversão ao risco.

Destacam-se como oportunidades para novas pesquisas: (i) analisar características comportamentais dos executivos na relação com sua compensação; (ii) investigar fatores macroeconômicos que podem interferir nos planos de remuneração; e (iii) identificar os possíveis efeitos moderadores das características da empresa, tais como níveis de governança corporativa.

\section{Referências}

ABRANTES, T. Os salários dos executivos das principais empresas da bolsa. Disponível em: <https://exame.abril.com.br/carreira/os-salarios-dos-executivos-das-principais-empresasda-bolsa/>. Acesso em: 25 jul. 2018.

ATTAWAY, M. A study of the relationship between company performance and CEO compensation. American Business Review, v. 18, n. 1, p. 77-85, 2000.

BAJTELSMIT, V. L.; BERNASEK, A. Why Do Women Invest Differently than Men? SSRN Electronic Journal, n. 970, 1996.

BALSAM, S. An Introduction to Executive Compensation. [s.1.] Academic Press, 2002.

BARBER, B. M.; ODEAN, T. Boys will be Boys: Gender, Overconfidence, and Common Stock Investment. The Quarterly Journal of Economics, v. 116, n. 1, p. 261-292, 2001.

BEBCHUK, L. A.; FRIED, J. M. Pay without Performance: The Unfulfilled Promise of Executive Compensation. [s.1.] Harvard University Press, 2004.

BEBCHUK, L.; FRIED, J. M.; WALKER, D. I. Managerial Power and Rent Extraction in the Design of Executive Compensation. University of Chicago Law Review, v. 69, p. 751-846, 2002.

BENNETT, B; BETTIS, J. C.; GOPALAN, R.; MILBOURN, T. Compensation goals and firm performance. Journal of Financial Economics, v. 124, n. 2, p. 307-330, 2017.

BERESKIN, F. L.; CICERO, D. C. CEO compensation contagion: Evidence from an exogenous shock. Journal of Financial Economics, v. 107, n. 2, p. 477-493, 2013.

BERTRAND, M.; SCHOAR, A. Managing with style: The effect of managers on firm policies. The Quarterly Journal of Economics, v. 118, n. 4, p. 1169-1208, 2003.

BRASIL. Lei N ${ }^{\circ}$ 6.404, de 15 de dezembro de 1976: Dispõe sobre as Sociedades por Ações. Brasília. Disponível em:

<http://www.planalto.gov.br/Ccivil_03/Leis/L6404compilada.htm>.Acesso em:25 jul.2018.

CAMPBELL, K.; MÍNGUEZ-VERA, A. Gender diversity in the boardroom and firm financial performance. Journal of Business Ethics, v. 83, n. 3, p. 435-451, 2008.

CONYON, M. J. Corporate governance and executive compensation. International Journal of Industrial Organization, v. 15, n. 4, p. 493-509, 1997.

CONYON, M. J. Executive Compensation and Incentives. Academy of Management, v. 20, n. 1, p. 25-44, 2006.

CONYON, M. J.; HE, L. Executive Compensation and Corporate Governance in China.

Journal of Corporate Finance, v. 17, n. 4, p. 1158-1175, 2011.

CORE, J. E.; GUAY, W.; LARCKER, D. F. The power of the pen and executive compensation. Journal of Financial Economics, v. 88, n. 1, p. 1-25, 2008. 
CORE, J. E.; GUAY, W. R.; LARCKER, D. F. Executive Equity Compensation and Incentives: A Survey. Economic Policy Review, v. 9, n. April, p. 27-50, 2003.

CORTEZ, C. Bônus para quem fica mais tempo na empresa. Disponível em: $<$ http://www2.valor.com.br/carreira/2852770/bonus-para- quem-fica-mais-tempo-naempresa>. Acesso em: 14 jul. 2017.

DAVIS, S. M. Developments, trends \& useful proposals for the attention of managers: No connection between executive age and corporate performance. Harvard Business Review, v. 23, n. 2, 1979.

EL-SAYED, N.; ELBARDAN, H. Executive Compensation, Corporate Governance and Corporate Performance: Evidence from the UK. Journal of Organisational Studies and Innovation, v. 3, n. 2, p. 31-49, 2016.

ELKINAWY, S.; STATER, M. Gender differences in executive compensation: Variation with board gender composition and time. Journal of Economics and Business, v. 63, n. 1, p. 2345, 2011.

ELLIG, B. R. The Complete Guide to Executive Compensation. [s.l.] McGraw-Hill, 2007.

FERNANDES, N. EC: Board compensation and firm performance: The role of "independent" board members. Journal of Multinational Financial Management, v. 18, n. 1, p. 30-44, 2008 .

FIRTH, M.; FUNG, P. M. Y.; RUI, O. M. Corporate performance and CEO compensation in China. Journal of Corporate Finance, v. 12, n. 4, p. 693-714, 2006.

FIRTH, M.; TAM, M.; TANG, M. The determinants of top management pay. Omega, v. 27, n. 6, p. 617-635, 1999.

FRANKEN, R. B. . The determinants of executive compensation An optimal mix in fixed and variable executive rewards for listed companies in the Netherlands. [s.1.] Tilburg University, 2010.

FRYDMAN, C.; JENTER, D. CEO Compensation. Annual Review of Financial Economics, v. 2, p. 75-102, 2010.

FUNCHAL, J. DE A.; TERRA, P. R. S. Remuneração de Executivos, Desempenho Econômico e Governança Corporativa: um Estudo Empírico em Empresas LatinoAmericanasEnANPADSalvador, 2006.

GHOSH, C.; SIRMANS, C. F. On REIT CEO compensation: Does board structure matter? Journal of Real Estate Finance and Economics, v. 30, n. 4, p. 397-428, 2005.

GIROUX, G. Executive Compensation : Accounting and Economic Issues. [s.1.] Business Expert Press, 2015.

GRAHAM, J. R.; HARVEY, C. R.; PURI, M. Managerial attitudes and corporate actions. Journal of Financial Economics, v. 109, n. 1, p. 103-121, 2013.

GUJARATI, D. N.; PORTER, D. C. Econometria Básica. 5. ed. McGraw-Hill Education, 2011.

HANLON, M.; RAJGOPAL, S.; SHEVLIN, T. Are executive stock options associated with future earnings? Journal of Accounting and Economics, v. 36, n. 1-3, p. 3-43, 2003.

HEALY, P. M.; WAHLEN, J. M. A Review of the Earnings Management Literature and Its Implications for Standard Setting. Accounting Horizons, v. 13, n. 4, p. 365-383, 1999. 
HEARN, B. The determinants of director remuneration, executive tenure and individual executive disclosure in North African IPO firms. Research in International Business and Finance, v. 27, n. 1, p. 162-182, 2013.

JENSEN, M. C.; MECKLING, W. H. Theory of the Firm: Managerial Behavior, Agency costs and Ownership Structure. Journal of Financial Economics, v. 3, p. 305-360, 1976.

JENSEN, M. C.; MURPHY, K. J. CEO Incentives - It ' s Not How Much You Pay, But How. Harvard Business Review, v. 3, n. 3, p. 138-153, 1990.

JIANAKOPLOS, N. A.; BERNASEK, A. Are women more risk averse? Economic inquiry, v. 36, n. 4, p. 620-630, 1998.

KATO, T.; KIM, W.; LEE, J. H. Executive compensation, firm performance, and Chaebols in Korea: Evidence from new panel data. Pacific Basin Finance Journal, v. 15, n. 1, p. 36-55, 2007.

KIEL, G. C.; NICHOLSON, G. J. Board Composition and Corporate Performance: how the Australian experience informs contrasting theories of corporate governance. Corporate Governance, v. 11, n. 3, p. 189-205, 2003.

KOLB, R. W. Too much is not enough: Incentives in executive compensation. [s.1.] Oxford University Press, 2012.

KUHN, K. M.; YOCKEY, M. D. Variable pay as a risky choice: Determinants of the relative attractiveness of incentive plans. Organizational Behavior and Human Decision Processes, v. 90, n. 2, p. 323-341, 2003.

LAM, K. C. K.; MCGUINNESS, P. B.; VIEITO, J. P. CEO gender, executive compensation and firm performance in Chinese-listed enterprises. Pacific Basin Finance Journal, v. 21, n. 1, p. 1136-1159, 2013.

LAWLER III, E. E. Strategic pay: aligning organizational strategies and pay systems. San Francisco: Jossey-Bass, 1990.

LIN, D.; KUO, H.; WANG, L. Chief executive compensation: An empirical study of fat cats CEOs. The International Journal of Business and Finance Research, v. 7, n. 2, p. 27-43, 2013.

LIPMAN, F. D.; HALL, S. E. Executive compensation best practices. New Jersey: John Wiley \& Sons, Inc., 2008.

MEHRAN, H. Executive compensation structure, ownership, and firm performance. Journal of Financial Economics, v. 38, n. 2, p. 163-184, 1995.

MURPHY, K. J. Executive Compensation. In: Handbook of Labor Economics. [s.l: s.n.]. v. 3p. 2485-2563, 1999.

MURPHY, K. J. Explaining Executive Compensation: Managerial Power vs. the Perceived Cost of Stock Options. University of Chicago Law Review, v. 69, n. 3, p. 847-869, 2002.

MURPHY, K. J. Executive Compensation: Where We Are, and How We Got There. In: Handbook of the Economics of Finance. [s.1: s.n.]. v. 2p. 211-356, 2013.

O’NEILL, G. L.; IOB, M. Determinants of executive remuneration in australian organizations: An exploratory study. Asia Pacific Journal of Human Resources, v. 37, n. 1, p. 65-75, 1999.

OAKLEY, J. G. Gender-based barriers to senior management positions: Understanding the scarcity of female CEOs. Journal of Business Ethics, v. 27, n. 4, p. 321-334, 2000. 
OZKAN, N. CEO Compensation and Firm Performance: An Empirical Investigation of UK Panel Data. European Financial Management, v. 17, n. 2, p. 260-285, 2011.

PENI, E. CEO and Chairperson characteristics and firm performance. Journal of Management and Governance, v. 18, n. 1, p. 185-205, 2014.

RAMALHO, A. Novo plano de cargos e salários da estatal vai valorizar o desempenho. Disponível em: <https://www.valor.com.br/empresas/5634099/novo-plano-de-cargos-esalarios-da-estatal-vai-valorizar-o-desempenho>. Acesso em: 25 jul. 2018.

SHIWAKOTI, R. K. Comparative analysis of determinants of executive remuneration in the UK financial services sector. Accounting and Finance, v. 52, p. 213-235, 2012.

SIGOLLO, R. Crise afeta salário e remuneração variável em todos os setores. Disponível em: <http://www.valor.com.br/carreira/4278722/crise-afeta-salario-e-remuneracao-variavelem- todos-os-setores $>$. Acesso em: 14 jul. 2017.

SILVEIRA, A. D. M. DA; BARROS, L. A. B. DE C. Concentration of Power and Corporate Performance Variabilityworking paper. [s.l: s.n.]. 2013. Disponível em: $<$ http://www.efmaefm.org/0EFMAMEETINGS/EFMA ANNUAL MEETINGS/2012Barcelona/papers/EFMA2012_0177_fullpaper.pdf>.

SOUZA, J. A. S. DE. Transações com partes relacionadas: determinantes e impactos no desempenho das empresas. [s.l.] Universidade Federal do Espírito Santo, 2014.

WANZENRIED, G. How feminine is corporate America? A recent overview. Journal of Economic Inequality, v. 6, n. 2, p. 185-209, 2008.

WHITE, H. A Heteroskedasticity-Consistent Covariance Matrix Estimator and a Direct Test for Heteroskedasticity. Econometrica, v. 48, n. 4, p. 817-838, 1980.

WOOD JUNIOR, T.; PICARELLI FILHO, V. Remuneração estratégica: a nova vantagem competitiva. 2. ed. São Paulo: Atlas, 1999.

YAN, Y. Determinants and Consequences of Executive Compensation: Empirical Evidence from Chinese Listed Companies. [s.1.] University of Bath, 2015.

YERMACK, D. Do Corporations Award Ceo Stock-Options Effectively. Journal of Financial Economics, v. 39, n. 2-3, p. 237-269, 1995. 